\title{
Active Fractions from Asparagus racemosus Willd. with Thrombolytic, Membrane Stabilizing and Free Radical Scavenging Activities
}

\author{
Md. Abdul Jali1 ${ }^{1 \Psi}$, Mohammad Sharifur $\operatorname{Rahman}^{2 \Psi}$, S. M. Ashikur Rahman ${ }^{1 \Psi}$, \\ Ridwan B. Rashid ${ }^{3}$ and Mohammad A. Rashid ${ }^{2}$ \\ ${ }^{1}$ Department of Pharmacy, State University of Bangladesh, Dhaka-1205, Bangladesh \\ ${ }^{2}$ Phytochemical Research Laboratory, Department of Pharmaceutical Chemistry, Faculty of Pharmacy, \\ University of Dhaka, Dhaka-1000, Bangladesh \\ ${ }^{3}$ Department of Microbiology, University of Dhaka, Dhaka-1000, Bangladesh
}

Received: June 25, 2015; Accepted: July 15, 2015; Published (Web): July 21, 2015

Bangladesh is a good repository of thousands of medicinal plants. Many plants have already been proven to be very effective for treating different diseases but they have not been evaluated scientifically enough to characterize the active fractions. Their safety profiles are yet to be explored and how they can be used to deal with other health related issues is to be assessed. Thrombosis and inflammation frequently develop complicated situations in human body. Free radicals make these states more complicated. To find better and safer molecules, comprehensive research on medicinal plant is going on around the world (Rahman et al., 2011; Rodriguez et al., 2012).

A. racemosus Willd. belongs to family Liliaceae and commonly known as 'Satamuli' in Bangladesh. It is a spinous under-shrub with tuberous and short rootstock. It is very well-known in the Ayurvedic system of medicine. This plant is used as galactagogue, antiulcer, aphrodisiac, carminative, stomachic, antiseptic, anxiolytic, antidepressive, analgesic, cardio protective, anti-HIV, etc. (Goyal et al., 2003; Potduang et al., 2008). Previous phytochemical investigations led to the isolation of shatavarins I-X, asparanin A, immunoside, isoflavones-8methoxy-5,6,4-trihydroxy isof-lavone-7-O-beta-Dglucopyranoside, flavanoid glycosides of quercitin, rutin and hyperoside, etc. (Alok et al., 2013).

A. racemosus Willd. is a popular herbal drug in Bangladesh. Previously, many studies have been done with $A$. racemosus extracts for biological assays. In maximum cases, these were limited only to crude alcoholic or aqueous extract. Some fractionation-based studies were conducted but polarity guided successive fractionation of the crude alcoholic or aqueous extract has not been followed (Hossain et al., 2012; Potduang et al., 2008; Shahriar et al., 2012). As a result, proper distribution of the secondary metabolites from parent crude extract into the fractions was not possible and therefore consistent biological activities can't be expected. This methodical approach is very important for standardization and characterization of plant-derived drugs. Once these are revealed, herbal practitioners might use them successfully to treat diseases and herbal formulators might prepare efficient market preparations from $A$. racemosus. With this aim, a systematic and comprehensive study of the root of $A$. racemosus was carried out and this paper reports the result of thrombolytic, membrane stabilizing and free radical scavenging activities.

The roots of $A$. racemosus were collected from Natore, Bangladesh in June 2013 and a voucher specimen (DACB accession no. 39561) representing this sample has been deposited at Bangladesh National Herbarium, Mirpur, Dhaka for future reference. The collected roots were chopped, dried and powdered. The powdered materials $(500 \mathrm{~g})$ were soaked in 1.5 litre methanol at room temperature for 7 days. The extract was filtered through cotton plug and concentrated with a rotary evaporator. An aliquot ( $5 \mathrm{~g}$ ) of the concentrated methanol extract was fractionated by the modified Kupchan method (VanWagenen et al., 1993)to provide petroleum ether (PE,

Correspondence to: Mohammad A. Rashid; Tel.: 880-2-9661920, Extn. 8137; Fax: 880-2-9667222; E-mail: rashidma@du.ac.bd;

${ }^{\Psi}$ These authors have equal contribution 
$0.80 \mathrm{~g}$ ), carbon tetrachloride (CT, $1.70 \mathrm{~g})$, chloroform (CF $1.10 \mathrm{~g}$ ) and aqueous (AQ $1.30 \mathrm{~g}$ ) soluble materials.

The in vitro thrombolytic assay was performed using venous blood from healthy volunteers (Prasad et al., 2006, 2007). Streptokinase (Altepase ${ }^{\circledR}$, Beacon Pharmaceuticals Ltd., Bangladesh) and distilled water were used as positive control and negative control, respectively. Percentage of clot lysis was expressed as:

\section{$\%$ thrombolysis $=($ weight of clot after treatment $/$ weight of clot before treatment) $\times 100$}

Membrane stabilizing activity was assessed by using two popular methods (Shinde et al., 1999; Sikder et al., 2012). In hypotonic solution-induced hemolysis assay, $500 \mu \mathrm{l}$ of erythrocyte suspension was mixed with $5 \mathrm{ml}$ of hypotonic solution $(50 \mathrm{mMNaCl})$ in $10 \mathrm{mM}$ sodium phosphate buffer saline $(\mathrm{pH} 7.4)$ containing either the extract $(2 \mathrm{mg} / \mathrm{ml})$ or reference drug, acetyl salicylic acid $(0.1 \mathrm{mg} / \mathrm{ml})$. The optical density (OD) of the supernatant was measured at $540 \mathrm{~nm}$. The percentage inhibition of hemolysis was calculated using the following equation:

$\%$ inhibition of hemolysis $=$

$$
\left\{\left(\mathrm{OD}_{\text {control }}-\mathrm{OD}_{\text {test samples }}\right) / \mathrm{OD}_{\text {control }}\right\} \times 100
$$

In case of heat-induced hemolysis method, $5 \mathrm{ml}$ of isotonic buffer containing aliquots of the different extractives $(2 \mathrm{mg} / \mathrm{ml})$ were mixed with erythrocyte suspension $(30 \mu \mathrm{l})$ and incubated at $54^{\circ} \mathrm{C}$ for $20 \mathrm{~min}$. The absorbance of the supernatant was measured at $540 \mathrm{~nm}$. The percentage inhibition of hemolysis was calculated according to the equation:

$\%$ Inhibition of hemolysis $=$

$$
\begin{aligned}
& \left\{1-\left(O D_{\text {heated test sample }}-O D_{\text {unheated test sample }}\right) /\right. \\
& \left.\left(O D_{\text {heated control sample }}-O D_{\text {heated test sample }}\right)\right\} \times 100
\end{aligned}
$$

The free radical scavenging activity of the extract was determined based on the scavenging activity of 1,1 diphenyl-2-picrylhydrazyl (DPPH) free radical (Chowdhury et al., 2010). Here, BHT (tert-butyl-1hydroxytoluene) and ascorbic acid were used as standards. Total phenolic content of the extractives were measured by using Folin-Ciocalteu reagent as an oxidizing agent and gallic acid as standard (Sikder et al., 2012). Total phenolic content was expressed as $\mathrm{mg}$ of GAE (gallic acid equivalent)/g of the dried extract.

In each assay, three replicates $(n=3)$ of each sample were used for statistical analysis and the values are reported as mean \pm standard deviation $(\mathrm{SD})$.

Thrombus formation leads to many vascular complexities in our body. Tissue plasminogen activator, urokinase, streptokinase, etc. are used abundantly for treating thrombosis but they are not above all limitations. So better thrombolytic agent is a demand of time (Hilleman and Campbell, 2011). With this view, the present study was conducted with crude methanolic extract of root of $A$. racemosus along with its petroleum ether, carbon tetrachloride, chloroform and aqueous soluble fractions (Figure 1). The highest thrombolytic activity was noticed by the chloroform soluble fraction. Saponins and flavonoids were previously reported to have significant thrombolytic activity (Fuentes et al., 2014). The root of A. racemosus is rich in saponins and flavonoids (Alok et al., 2013) and why this might be a reason this plant displays significant thrombolytic activity.

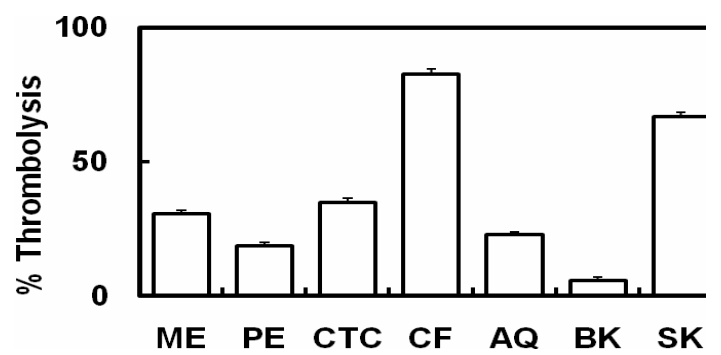

Figure 1. Effect of different extractives of A. racemosuson thrombolysis. Here, ME: crude methanolic extract; PEpetroleum ether soluble fraction of methanolic extract; CTCcarbon tetrachloride soluble fraction of methanolic extract; CF- chloroform soluble fraction of methanolic extract; AQaqueous fraction; BK-blank (negative control); SKstreptokinase (positive control).

Membrane stabilization assay can screen out the antiinflammatory materials. When erythrocytes are exposed to hypotonic medium, heat, methyl salicylate, phenylhydrazine, etc., the lysis of the membranes occurs (Halliwell and Whiteman, 2004). Free radical induced lipid peroxidation makes this hemolysis more susceptible (Shinde et al., 1999). Membrane stabilization leads to the prevention of leakage of serum protein and fluids into the tissues during the action of inflammatory mediators (Jean- 
Gilles et al., 2012). The membrane stabilizing activities of the root of $A$. racemosusare displayed in figure 2 . Considering together the hypotonic solution-induced hemolysis (Figure 2A) and heat-induced hemolysis (Figure 2B), the aqueous fraction exhibited the maximum protection to the membrane. As this plant produces a lot of saponins and flavonoids (Alok et al., 2013), its strong anti-inflammatory activity might be justified by these biosynthesized metabolites (Conner and Grisham, 1996).
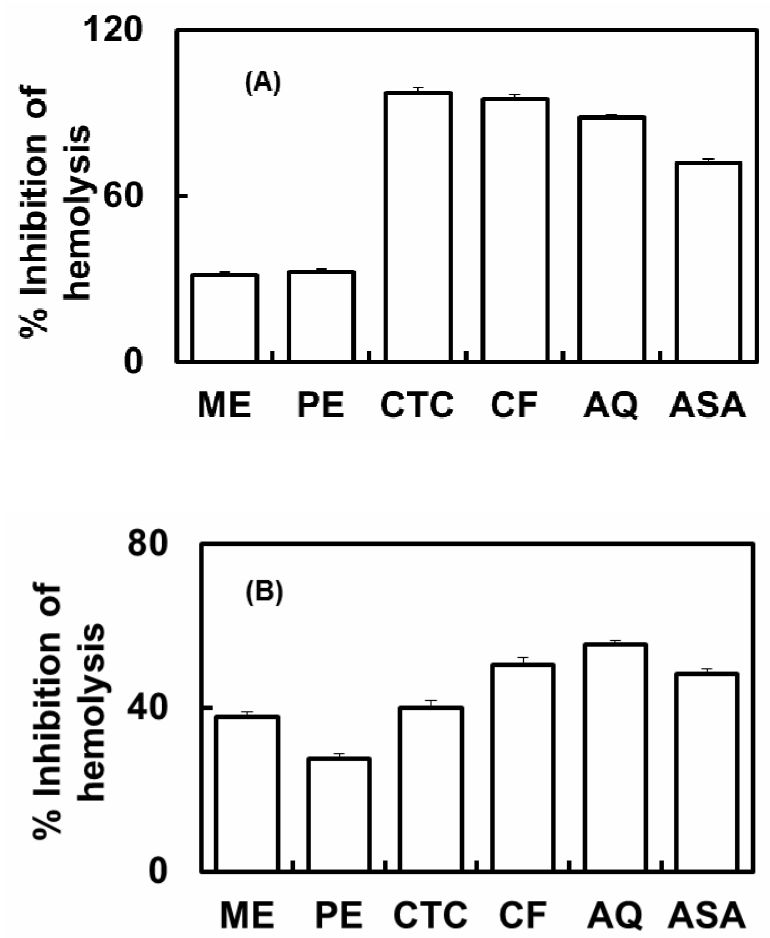

Figure 2. Effect of different extractives of A. racemosuson hypotonic solution induced (A) and heat induced (B) hemolysis of erythrocyte membrane. In both cases, ME: crude methanolic extract; PE- petroleum ether soluble fraction of methanolic extract; CTC- carbon tetrachloride soluble fraction of methanolic extract; $\mathrm{CF}$ - chloroform soluble fraction of methanolic extract; AQ- aqueous fraction; ASAacetylsalicylic acid (standard drug).

Free radicals are known to cause of inflammatory damages and promote associated problems afterwards (Schetter et al., 2010). To counteract the problems generated by free radicals, antioxidants might of great help. Different fractions of A. racemosus were subjected to DPPH free radical scavenging assay, where the chloroform fraction scavenged free radicals prominently (Figure 3). It is known that phenolic compounds are very useful to serve as antioxidants. So, the total phenolic content of A. racemosus root fractions was determined (Figure 4) and the chloroform fraction also displayed higher level of phenolic content. This finding explains a reason for the stronger free radical scavenging ability of the chloroform fraction of the roots.

The root partitionates of $A$. racemosuswere evaluated comprehensively to check their thrombolytic, membrane stabilization and free radical scavenging actions. The polar fractions of the crude methanol extract were found very

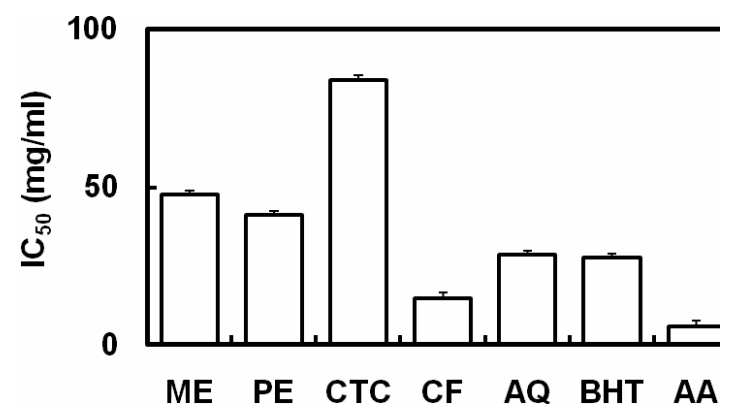

Figure $3 . \mathrm{IC}_{50}$ values of the standard and partitionates of the root of A. racemosus. Here, ME: crude methanolic extract; PEpetroleum ether soluble fraction of methanolic extract; CTCcarbon tetrachloride soluble fraction of methanolic extract; $\mathrm{CF}$ - chloroform soluble fraction of methanolic extract; AQaqueous fraction; BHT-tert-butyl-1-hydroxy-toluene (standard); AA-ascorbic acid (standard).

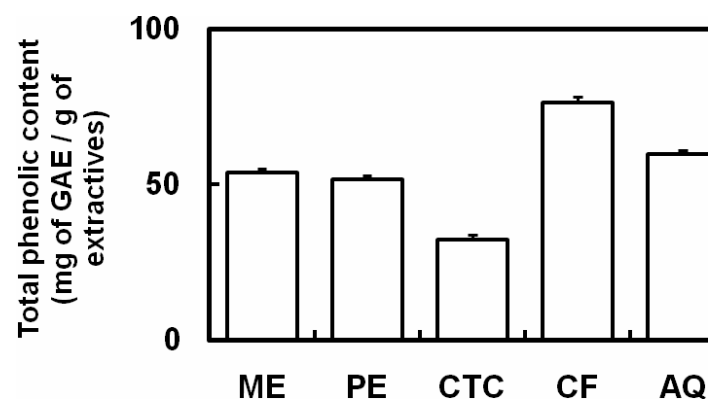

Figure 4. Total phenolic contents of the root extractivesof $A$. racemosus. Here, GAE- gallic acid equivalent; ME: crude methanolic extract; PE- petroleum ether soluble fraction of methanolic extract; CTC- carbon tetrachloride soluble fraction of methanolic extract; $\mathrm{CF}$ - chloroform soluble fraction of methanolic extract; AQ-aqueous fraction.

rich in phenolic antioxidants and they showed higher level of thrombolysis and membrane stabilization. Herbal formulators might use this information to prepare potent and efficient drug preparations and the herbal practitioner might consider the use of polar partitionates of the root for treating cardiovascular and inflammatory disorders. 
Further investigations are required to know their detailed underlying mechanism.

\section{References}

Alok, S., Jain, S.K., Verma, A., Kumar, M., Mahor, A. and Sabharwal, M. 2013. Plant profile, phytochemistry and pharmacology of Asparagus racemosus (Shatavari): a review. Asian Pac. J. Trop. Dis. 3, 242-251.

Chowdhury, A., Alam, M.A., Rahman, M.S., Hassan, M.A. and Rashid, M.A. 2010. Antioxidant, antimicrobial and cytotoxic activities of Corypha taliera Roxb. Latin Am. J. Pharm. 29, 1231-1234.

Conner, E.M. and Grisham, M.B. 1996. Inflammation, free radicals and antioxidants. Nutrition 12, 274-277.

Fuentes, E., Guzmán, L., Alarcón, M., Moore, R. and Palomo, I. (2014). Thrombolytic/fibrinolytic mechanism of natural products. (InTech). Dr. Krasimir Kolev (Ed.), ISBN: 978953-51-1265-5, InTech, DOI:10.5772/57608. Available from: http://www. intechopen.com/books/fibrinolysis-andthrombolysis/ thrombolytic-fibrinolytic-mechanism-ofnatural-products

Goyal, R.K., Singh, J. and Lal, H. 2003. Asparagus racemosusan update. Indian J. Med. Sci. 57, 408-414.

Halliwell, B. and Whiteman, M. 2004. Measuring reactive species and oxidative damage in vivo and in cell culture: how should you do it and what do the results mean? $\mathrm{Br}$. $J$. Pharmacol. 142, 231-255.

Hilleman, D. and Campbell, J. 2011. Efficacy, safety and cost of thrombolytic agents for the management of dysfunctional hemodialysis catheters: a systematic review. Pharmacotherapy 31, 1031-1040.

Hossain, M.I., Sharmin, F.A., Akhter, S., Bhuiyan, M.A. and Shahriar, M. 2012. Investigation of cytotoxicity and in-vitro antioxidant activity of Asparagus racemosus root extract. Int. Curr. Pharm. J. 1, 250-257.

Jean-Gilles, D., Li, L., Ma, H., Yuan, T., Chichester, C.O. and Seeram, N.P. 2012. Anti-inflammatory effects of polyphenolic-enriched red raspberry extract in an antigeninduced arthritis rat model. J. Agric. Food Chem. 60, 57555762 .
Potduang, B., Meeploy, M., Giwanon, R., Benmart, Y., Kaewduang, M. and Supatanakul, W. 2008. Biological activities of Asparagus racemosus. Afr. J. Tradit. Complement Altern. Med. 5, 230-237.

Prasad, S., Kashyap, R.S., Deopujari, J.Y., Purohit, H.J., Taori, G.M. and Daginawala, H.F. 2006. Development of an in vitro model to study clot lysis activity of thrombolytic drugs. Thromb. J. 4, 14

Prasad, S., Kashyap, R.S., Deopujari, J.Y., Purohit, H.J., Taori, G.M. and Daginawala, H.F. 2007. Effect of Fagonia arabica (Dhamasa) on in vitro thrombolysis. BMC Complement. Altern. Med. 7, 36.

Rahman, M.S., Rahman, M.Z., Begum, B., Chowdhury, R., Islam, S.N. and Rashid, M.A. 2011. Antidiabetic principle from Eclipta prostrata. Latin Am. J. Pharm. 30, 1656-1660.

Rodriguez, A.L., Wojcik, B.M., Wrobleski, S.K., Myers, D.D., Wakefield, T.W. and Diaz, J.A. 2012. Statins, inflammation and deep vein thrombosis: a systematic review. J. Thromb. Thrombolysis. 33, 371-382.

Schetter, A.J., Heegaard, N.H. and Harris, C.C. 2010. Inflammation and cancer: interweaving microRNA, free radical, cytokine and p53 pathways. Carcinogenesis 31, 3749.

Shahriar, M., Sharmin, F.A., Islam, S.A., Dewan, I. and Kabir, S. 2012. Membrane stabilizing and anti-thrombolytic activities of four medicinal plants of Bangladesh. Experiment 4, 265270.

Shinde, U.A., Phadke, A.S., Nair, A.M., Mungantiwar, A.A., Dikshit, V.J. and Saraf, M.N. 1999. Membrane stabilizing activity - a possible mechanism of action for the antiinflammatory activity of Cedrus deodara wood oil. Fitoterapia 70, 251-257.

Sikder, M.A.A., Kaisar, M.A., Rashid, M.A., Millat, M.S. and Sultana, A. 2012. In vitro membrane stabilizing activity, total phenolic content, cytotoxic, thrombolytic and antimicrobial activities of Calliandra surinamensis (Wall.). J. Pharmacogn. Phytochem. 1, 45-50.

VanWagenen, B.C., Larsen, R., Cardellina, J.H., Randazzo, D., Lidert, Z.C. and Swithenbank, C. 1993. Ulosantoin, a potent insecticide from the sponge Ulosa ruetzleri. J. Org. Chem. 58, 335-337. 